\title{
Significant and persistent impact of timber harvesting on soil microbial communities in Northern coniferous forests
}

Martin Hartmann, Charles G Howes, David VanInsberghe, Hang Yu, Dipankar Bachar, Richard Christen, Rolf Henrik Nilsson, Steven J Hallam and William W Mohn

The ISME Journal (2012) 6, 2320; doi:10.1038/ismej.2012.100

Correction to: The ISME Journal (2012) 6, 2199-2218; doi:10.1038/ismej.2012.84; published online 2 August 2012

Since the publication of this article, the authors have noticed errors in two sentences that appeared within the online version of their paper.

The errors have now been rectified, and the correct article appears in this issue. The html and online pdf versions have also been rectified, and now carry the correct paper. The amended sentences are also shown here.

The authors would like to apologise for any inconvenience this may have caused.

\section{Page 3:}

The three levels of OM removal were defined as stem-only harvesting (OM1), whole-tree harvesting
(OM2) and whole-tree harvesting plus forest floor removal (OM3), and resulted in average percent net carbon removal of $51 \pm 4$ (95\% confidence interval), $65 \pm 3$ and $84 \pm 2$, respectively (Marty Kranabetter, BC Ministry of Forests, personal communication). The three levels of soil compaction were defined as none (C0), moderate (C1) and severe (C2), and resulted in average percent increases in bulk density of $4 \pm 4,20 \pm 4$ and $19 \pm 4$, respectively, when compared with the reference plots. Ten years after harvesting, the percent increase in bulk density in these soil systems remained at $4 \pm 5,14 \pm 6$ and $15 \pm 6$, respectively.

\section{Page 13:}

On average, the uncompacted C0 treatments experienced an increase in bulk density equivalent to $20 \%$ of the maximum bulk density observed in C1. 